\title{
Polyene Sensitivity during Germination of Conidia of Aspergillus fumigatus
}

\author{
By N. J. RUSSELL, D. KERRIDGE AND E. F. GALE \\ Sub-department of Chemical Microbiology, Department of Biochemistry, \\ University of Cambridge, Cambridge $C B 2$ I $Q W$
}

(Received 25 November 1974)

\begin{abstract}
SUMMARY
A system for the rapid and relatively synchronous germination of conidia from a clinical isolate of Aspergillus fumigatus is described. The polyene-mediated release of $\mathrm{K}^{+}$from germinating conidia has been determined. Ungerminated conidia were insensitive to amphotericin B methyl ester (AME) at concentrations $>50 \mu \mathrm{g} / \mathrm{ml}$, but rapidly became sensitive to I to $2 \mu \mathrm{g} \mathrm{AME} / \mathrm{ml}$ during the initial stages of germination. These findings have been correlated with minimum inhibitory concentration values obtained in studies of conidial germination and hyphal outgrowth using a variety of growth tests.
\end{abstract}

\section{INTRODUCTION}

As part of a wider study of the biochemistry of 'opportunistic fungi', it was necessary to monitor the sensitivity of germinating conidia of Aspergillus fumigatus to the polyene antibiotics. The methods available for measuring antibiotic sensitivity in fungi include growth tests in the presence of the antibiotic, measurements of a parameter of growth, e.g. hyphal extension, or of a particular metabolic function. The widely used growth tests pose many problems because the system under study is a rapidly differentiating one with early stages of conidial germination culminating in the emergence of a germ tube within 6 to $7 \mathrm{~h}$. Long-term growth tests do not differentiate between the effects of the antibiotic on spore germination and hyphal extension. The polyene antibiotics are unstable and virtually insoluble in water so that growth tests are inherently insensitive and unreliable; consequently, long-term growth tests cannot be considered as suitable assays for polyene sensitivity. The polyene used in these studies, amphotericin B methyl ester (AME), is readily water dispersible and so could be used in liquid media although its diffusibility in solid media must be queried. The question arises whether the morphological changes observed microscopically during conidial germination (i.e. a phase darkening of the normally phase-bright conidia, followed by swelling and outgrowth of the germ tube) could be arrested at any particular stage by addition of antibiotic and thereby used as an indicator of antibiotic action. One of the disadvantages of such a system would be that it depends upon the interaction of the polyene with conidia, and it is possible that antibiotic bound at an insensitive stage might be retained and as a result inhibit at a later sensitive stage. It is known from previous studies of the effects of polyene antibiotics on Candida albicans that they exert a time-dependent action (Gale, 1974) which might invalidate a similar approach using Aspergillus conidia. Measurement of parameters such as conidial swelling or hyphal extension in the presence of the antibiotic may give a quantititative estimate of antibiotic sensitivity, but do not lend themselves to rapid routine assay. What is required is a specific metabolic function or feature that can be monitored continuously. The leakage of $\mathrm{K}^{+}$was 
chosen on the basis of previous studies using the dimorphic yeast C. albicans (Gale, 1974) since all polyenes tested cause the release of $\mathrm{K}^{+}$ions from sensitive organisms (Lampen, 1966; Zygmunt, 1966). The values of antibiotic concentration or amount of $\mathrm{K}^{+}$released are in some respects arbitrary and ideally should be correlated with growth tests. However, provided that the rate of $\mathrm{K}^{+}$release used to define sensitivity to the antibiotic is standardized, changes in polyene concentration required to produce this rate of $\mathrm{K}^{+}$release are still meaningful, i.e. the value obtained may not be an absolute value of polyene sensitivity but it is a reliable relative estimate. The advantage of using $\mathrm{K}^{+}$release as an estimate of polyene action is that it is a rapid and sensitive test which can be monitored continuously and can consequently give information on changes in antibiotic sensitivity that might occur during conidial germination. We describe experiments in which $\mathrm{K}^{+}$release in the presence of AME was correlated with conidial viability and fungal growth measured by a variety of growth tests.

\section{METHODS}

Source and growth of Aspergillus fumigatus. The strain of A. fumigatus was a clinical isolate obtained from the Mycological Reference Laboratory, London School of Hygiene and Tropical Medicine, London. All stocks were grown at $37^{\circ} \mathrm{C}$ on slopes of Czapek-Dox agar (Oxoid Ltd; containing $(\mathrm{g} / \mathrm{l}): \mathrm{NaNO}_{3}, 2 \cdot 0 ; \mathrm{KCl}, 0.5$; magnesium glycerophosphate, $0.5 ; \mathrm{FeSO}_{4}, 0.0 \mathrm{I} ; \mathrm{K}_{2} \mathrm{SO}_{4}, 0.35 ;$ sucrose, $30.0 ; \mathrm{pH} \mathrm{6.8)} \mathrm{in} \mathrm{McCartney} \mathrm{bottles} \mathrm{and} \mathrm{subcultured}$ at Io-day intervals. Conidial suspensions were prepared from Io-day-old slopes. The conidia were carefully washed from slopes with $5 \mathrm{ml}$ sterile $0 . \mathrm{I} \%(\mathrm{w} / \mathrm{v})$ Tween 80 followed by $5 \mathrm{ml}$ sterile distilled water. The conidia were harvested by centrifugation, washed twice with sterile distilled water and the suspension density determined by using a haemocytometer. Conidia harvested from ro-day-old slopes which had been stored at $4{ }^{\circ} \mathrm{C}$ for a further 2 weeks showed no change in the timing and pattern of germination.

For germination experiments, washed conidia were suspended at a final density of $10^{7}$ spores/ml in Czapek-Dox medium supplemented with $0.1 \%$ (w/v) Casamino acids (Difco). All germination experiments in liquid media were performed at $37^{\circ} \mathrm{C}$ in a reciprocal shaking water bath.

Growth and viability tests. For growth on agar-containing medium in the presence of the polyene, the required amount of antibiotic was mixed with molten Czapek-Dox + Casamino acids $\left(0 \cdot 1 \%\right.$, w/v) agar at $45{ }^{\circ} \mathrm{C}$ and plates poured immediately. After cooling and drying the plates, suspensions of conidia were spread on the surface. In those experiments in which conidial viability was examined after incubation in the presence or absence of AME (which was dissolved in water on the day of use) the conidia were dispersed in solid media minus the antibiotic. Samples ( $\mathrm{I} \mathrm{ml}$ ) of the appropriate serial dilutions were mixed with $20 \mathrm{ml}$ molten Czapek-Dox + Casamino acids $(\mathrm{I} \cdot 0 \% \mathrm{w} / \mathrm{v})$ agar at $45^{\circ} \mathrm{C}$ and poured immediately. All plates were incubated at $37^{\circ} \mathrm{C}$ in the dark to minimize light-dependent polyene degradation. The size of formalin-fixed $(0.1 \%, w / v$, final concentration) germinating conidia was measured microscopically with a Leitz Ortholux microscope. Preparations were photographed by means of Ilford Pan F film with a Leitz Orthomat camera. Negatives were projected on to a white surface at a fixed distance and the longest dimension of the conidia measured. The enlargement was $\times 3240$, giving an image of the ungerminated conidium of approximately $\mathrm{I} \mathrm{cm}$ diam.

Determination of potassium release. Conidia were suspended at a final density of $10^{7} / \mathrm{ml}$ in $20 \mathrm{ml} 0.03 \mathrm{M}$-tris- $\mathrm{HCl}$ buffer $\mathrm{pH} 7.5$ at room temperature. The release of potassium was estimated by using a $\mathrm{K}^{+}$-sensitive electrode (type $\mathrm{BH}$ I I5, Electronic Instruments Ltd, 


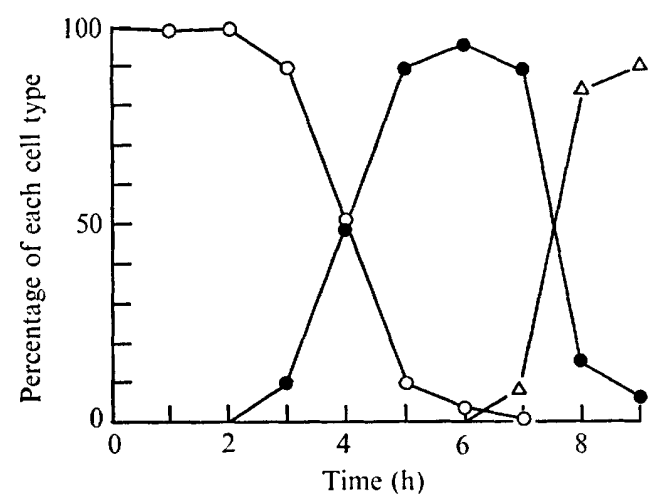

Fig. I

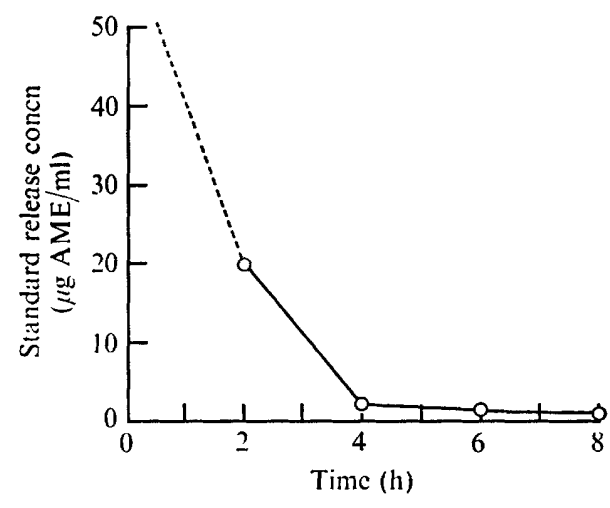

Fig. 2

Fig. I. The germination of conidia of $A$. fumigatus. Freshly harvested conidia were resuspended in Czapek-Dox medium supplemented with $0.1 \%(\mathrm{w} / \mathrm{v})$ Casamino acids at a density of $10^{7} / \mathrm{ml}$ and incubated aerobically at $37^{\circ} \mathrm{C}$. Samples were withdrawn at intervals and the percentages $(O)$ ungerminated, $(\bullet)$ swollen and $(\triangle)$ with germ tubes determined microscopically.

Fig. 2. The effect of $\mathrm{AME}$ on $\mathrm{K}^{+}$release (expressed as s.r.c. values) by germinating conidia of A. fumigatus. Freshly harvested conidia were resuspended in Czapek-Dox medium supplemented with $0.1 \%(\mathrm{w} / \mathrm{v})$ Casamino acids at a density of $10^{7} / \mathrm{ml}$ and incubated aerobically at $37^{\circ} \mathrm{C}$. Samples were withdrawn at intervals for the determination of the effect of $\mathrm{AME}$ on $\mathrm{K}^{+}$release.

Richmond, Surrey) as detailed by Gale (1974). Gale (1974) defined and discussed the use of the term 'standard release concentration' (s.r.c.); in the experiments reported here, s.r.c. corresponds to the concentration of antibiotic required to produce in $8 \mathrm{~min}$ a standard release of $\mathrm{I} \mathrm{nmol} \mathrm{K} \mathrm{K}^{+} / \mathrm{min} / \mathrm{IO}^{7}$ conidia above the release in control conidia. A similar timeand polyene concentration-dependent release of $\mathrm{K}^{+}$to that described by Gale (1974) for C. albicans was observed in these experiments with germinating conidia of $A$. fumigatus. It was found impractical to measure $\mathrm{K}^{+}$release from germinating conidia after more than $8 \mathrm{~h}$ incubation in a germination medium because the hyphae have grown by that time to such a length that clumping occurs, and also hyphae are prone to breakage by shear during the constant stirring required for reliable estimation of $\mathrm{K}^{+}$release.

\section{RESULTS}

A number of clinical isolates of $A$. fumigatus were examined for the ability of their conidia to germinate in a defined liquid medium. The strains showed great variability in the time course of their germination, degree of synchrony and liability to clump. One isolate of A. fumigatus, strain 2085, was chosen for further study on the basis that it produced conidia freely on solid media; in liquid media the conidial germination was high ( $>95 \%$ ), synchronous and relatively rapid, germ tubes being produced within $8 \mathrm{~h}$ (Fig. I). Clumping of conidia did not occur during the early stages of germination. Suspensions of germinating conidia were scored for phase 'brightness', 'swollen' (i.e. twice the original linear dimensions), and 'germ tubes'.

Germination could be arrested at any stage by cooling the conidia to $0{ }^{\circ} \mathrm{C}$ or by washing and resuspending them in water. Moreover, if the carbon or nitrogen source was omitted from the Czapek-Dox medium conidia did not germinate. This is in contrast to the finding by Campbell (I97I) that up to $20 \%$ of conidia of $A$. fumigatus (strain T $30 \mathrm{e} / \mathrm{I}$ ) germinated in 


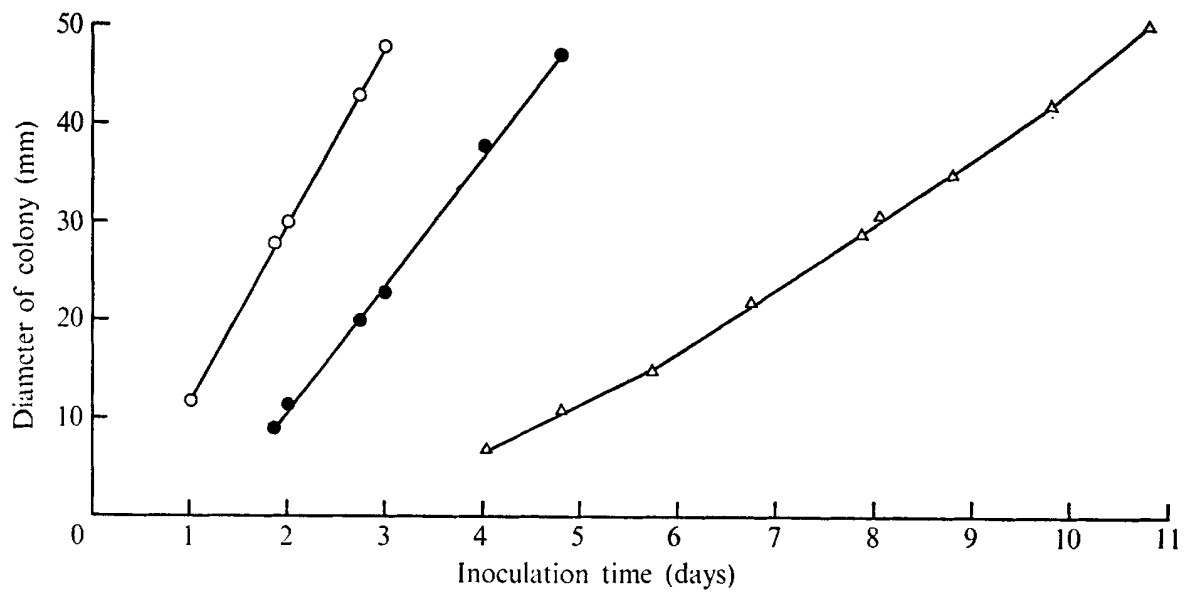

Fig. 3. The effect of AME on the radial colonial growth of $A$. fumigatus. Conidia were inoculated on to the surface of Czapek-Dox agar plates containing AME as required. The plates were incubated at $37^{\circ} \mathrm{C}$ in the dark and the colony diameter measured at intervals. $\mathrm{O}$, Control;, $3 \mu \mathrm{g}$ AME/ $\mathrm{ml} ; \triangle$, $10 \mu \mathrm{g} \mathrm{AME} / \mathrm{ml}$.

distilled water; other differences between our results and Campbell's (I97I) almost certainly reflect strain differences. Thus, strain 2085 provides a satisfactory system in which to study conidial germination.

\section{Polyene sensitivity determined by means of $\mathrm{K}^{+}$release}

Conidia germinating in the supplemented Czapek-Dox medium were washed twice with $0.03 \mathrm{M}$-tris- $\mathrm{HCl}$ buffer for assay of $\mathrm{K}^{+}$release. AME was added at a range of concentrations and the standard release concentration determined. The rate of $\mathrm{K}^{+}$release chosen was arbitrary in the sense that it had to be an experimentally convenient one, since multiple samples were assayed at short time-intervals during germination. However, an attempt was made to use a rate of $\mathrm{K}^{+}$release that gave s.r.c. values that were meaningful in terms of growth tests (see later). There was a precipitous fall in the concentration of AME required to achieve the standard rate of $\mathrm{K}^{+}$release during germination (Fig. 2). Freshly harvested conidia were insensitive to AME, the addition of $50 \mu \mathrm{g} \mathrm{AME} / \mathrm{ml}$ failing to increase the rate of $\mathrm{K}^{+}$release above the control value. Higher concentrations were not used in view of the poor solubility of AME in water and the doubtful significance of any results that would be obtained. After $2 \mathrm{~h}$, when the conidia had become phase-dark, they were sensitive to $20 \mu \mathrm{g} \mathrm{AME} / \mathrm{ml}$; after $4 \mathrm{~h}$, when virtually all the conidia had swollen to twice their original size, they were sensitive to I to $2 \mu \mathrm{g} \mathrm{AME} / \mathrm{ml}$. The latter level of sensitivity was maintained throughout the emergence of the germ tubes and outgrowth of hyphae.

\section{Polyene sensitivity determined by means of growth tests}

An alternative approach using a growth test was to allow conidia to germinate on agar plates containing a range of concentrations of AME. Growth was inhibited at all concentrations tested when scored after $24 \mathrm{~h}$, but on continued incubation mycelial development was observed and the colonies extended at antibiotic concentrations up to $10 \mu \mathrm{g} / \mathrm{ml}$. The rate of colonial growth was progressively reduced in the presence of 3 and $10 \mu \mathrm{g}$ AME $/ \mathrm{ml}$. In contrast to the control and to a concentration of $3 \mu \mathrm{g} \mathrm{AME} / \mathrm{ml}$, the radial growth rate in the presence of Io $\mu \mathrm{g} \mathrm{AME} / \mathrm{ml}$ increased during the course of the experiment (Fig. 3). No growth was observed at $30 \mu \mathrm{g} \mathrm{AME} / \mathrm{ml}$. 
Table I. Effect of prolonged exposure to AME on viability of germinating conidia of $A$. fumigatus

Conidia (approx. $10^{7} / \mathrm{ml}$ ) were incubated in Czapek-Dox supplemented with $0.1 \%(\mathrm{w} / \mathrm{v}$ ) Casamino acids, with AME added as required. Viability was determined after serial dilution by plating in antibiotic-free medium.

\begin{tabular}{|c|c|c|c|c|c|c|c|}
\hline \multirow{2}{*}{$\begin{array}{c}\text { Time } \\
\text { (h) }\end{array}$} & \multicolumn{7}{|c|}{$10^{-5} \times$ Viable conidia $/ \mathrm{ml}$ at an AME concn $(\mu \mathrm{g} / \mathrm{ml})$ of: } \\
\hline & 0 & $0 \cdot I$ & 0.3 & I & 3 & IO & 30 \\
\hline o & 65 & 46 & 36 & 48 & 57 & 58 & 63 \\
\hline $\mathbf{I}$ & 60 & I 13 & 85 & 59 & 58 & 37 & 13 \\
\hline 4 & 39 & 53 & 48 & 44 & 20 & 15 & 9 \\
\hline 6 & 74 & 74 & 86 & 45 & 14 & 16 & 5 \\
\hline
\end{tabular}

In attempts to correlate $\mathrm{K}^{+}$release with the effects of $\mathrm{AME}$ on conidial viability and hyphal extension the following experiments were performed. In the first, AME at final concentrations of $0 . \mathrm{I}, 0.3, \mathrm{I}, 3, \mathrm{I} 0$ and $30 \mu \mathrm{g} / \mathrm{ml}$ was added at zero time to suspensions of conidia in a complete growth medium. At o, I, 4 and $6 \mathrm{~h}$, samples from each incubation were serially diluted with sterile $0.8 \%(\mathrm{w} / \mathrm{v}) \mathrm{NaCl}$, plated out in Czapek-Dox agar and incubated at $37^{\circ} \mathrm{C}$. The colonies were scored after $36 \mathrm{~h}$ when two effects of the antibiotic were noted, one concentration-dependent and the other time-dependent (Table I). After $\mathrm{I} \mathrm{h}$ in the presence of up to $3 \mu \mathrm{g} \mathrm{AME} / \mathrm{ml}$ there was no reduction in conidial viability; at Io and $30 \mu \mathrm{g} \mathrm{AME} / \mathrm{ml}$ there was respectively 36 and $80 \%$ reduction in conidial viability. After $4 \mathrm{~h}$ in the presence of I $\mu \mathrm{g} \mathrm{AME} / \mathrm{ml}$ there was no significant reduction in conidial viability; at 3, Io and $30 \mu \mathrm{g} \mathrm{AME} / \mathrm{ml}$ there was respectively 65,74 and $86 \%$ reduction in conidial viability. No significant change in this pattern was observed after $6 \mathrm{~h}$ in the presence of the antibiotic.

In a second experiment conidia were incubated in a germination medium, and at $0,1,4$ and $6 \mathrm{~h}$ samples were removed and transferred to flasks containing sufficient AME to give final concentrations of I, 3, IO and $30 \mu \mathrm{g} \mathrm{AME} / \mathrm{ml}$. Incubation in the presence of the antibiotic was continued for $30 \mathrm{~min}$ before serial dilution of the suspension for the determination of conidial viability. An incubation period of $30 \mathrm{~min}$ was chosen since this was the maximum time to determine antibiotic sensitivity by means of $\mathrm{K}^{+}$release, and it was hoped that some correlation between the two methods for determining polyene sensitivity could be achieved. After $\mathrm{I} \mathrm{h}$ in a germination medium, a further $30 \mathrm{~min}$ in the presence of polyene resulted in reductions in viability ranging from $26 \%$ in the presence of I $\mu \mathrm{g} \mathrm{AME} / \mathrm{ml}$ to $57 \%$ in the presence of $30 \mu \mathrm{g} \mathrm{AME} / \mathrm{ml}$. After $4 \mathrm{~h}$ in the germination medium, a further $30 \mathrm{~min}$ in the presence of I $\mu \mathrm{g} \mathrm{AME} / \mathrm{ml}$ resulted in an $80 \%$ reduction in viability. In the presence of $3 \mu \mathrm{g} \mathrm{AME} / \mathrm{ml}$ the reduction in viable count was $>97 \%$ (Table 2 ). There was no significant change in this pattern when conidia which had been incubated in the complete medium for $6 \mathrm{~h}$ were exposed to AME for $30 \mathrm{~min}$.

\section{Polyene sensitivity assayed by using morphological parameters}

Since during the early stages of germination $\mathrm{K}^{+}$release was insensitive to and viability was unaffected by $<3 \mu \mathrm{g} \mathrm{AME} / \mathrm{ml}$, we investigated whether any morphological development could occur under these conditions. Accordingly an experiment was designed to test whether germination was inhibited by the addition of AME at various stages during the developmental process. At $2 \mathrm{~h}$ intervals, samples were withdrawn from a suspension of germinating conidia and transferred to flasks containing sufficient $\mathrm{AME}$ to give final concentrations of $0 . \mathrm{I}, 0.3,1.0$ and $3.0 \mu \mathrm{g} / \mathrm{ml}$, and the incubation was continued at $37^{\circ} \mathrm{C}$. 
Table 2. Effect of brief exposure to AME on viability of germinating conidia of $A$. fumigatus

Conidia (approx. $10^{7} / \mathrm{ml}$ ) were incubated in Czapek-Dox medium supplemented with $0 \cdot 1 \%(\mathrm{w} / \mathrm{v})$ Casamino acids. At the times indicated, samples were withdrawn and incubated for a further $30 \mathrm{~min}$ in the presence of AME before determination of viability.

\begin{tabular}{|c|c|c|c|c|c|}
\hline \multirow{2}{*}{$\begin{array}{c}\text { Time } \\
\text { (h) }\end{array}$} & \multicolumn{5}{|c|}{$10^{-5} \times$ Viable conidia $/ \mathrm{ml}$ at an AME concn $(\mu \mathrm{g} / \mathrm{ml})$ of: } \\
\hline & 0 & I & 3 & 10 & 30 \\
\hline 0 & 69 & 53 & 85 & 72 & 107 \\
\hline I & $6 I$ & 42 & 45 & 33 & 27 \\
\hline 4 & 60 & II & 2 & I & 0.5 \\
\hline 6 & 60 & 28 & 2 & 0.5 & 0.3 \\
\hline
\end{tabular}

Table 3. Effect of AME on conidial swelling and hyphal extension in A. fumigatus

Conidia (approximately $10^{7} / \mathrm{ml}$ ) were incubated in Czapek-Dox medium supplemented with $0.1 \%$ (w/v) Casamino acids. At the times indicated, AME was added as required. Samples were withdrawn at various times during the subsequent incubation and after fixation the longest dimension of at least 100 conidia or germinating conidia measured microscopically.

\begin{tabular}{|c|c|c|c|c|c|c|}
\hline \multirow{2}{*}{$\begin{array}{l}\text { Time of } \\
\text { addition } \\
\text { (h) }\end{array}$} & \multirow{2}{*}{$\begin{array}{c}\text { Time } \\
\text { sampled } \\
\text { (h) }\end{array}$} & \multicolumn{5}{|c|}{$\begin{array}{l}\text { Largest dimension of germinating conidia ( } \mu \mathrm{m} \pm \text { S.D. }) \\
\text { at an AME concn }(\mu \mathrm{g} / \mathrm{ml}) \text { of: }\end{array}$} \\
\hline & & 0 & $O \cdot I$ & 0.3 & I & 3 \\
\hline \multirow[t]{5}{*}{0} & 0 & $3.3 \pm 0.04$ & & & & \\
\hline & 2 & $3.2 \pm 0.12$ & $3.4 \pm 0.09$ & $3.3 \pm 0.09$ & $3.5 \pm 0.03$ & $3.3 \pm 0.12$ \\
\hline & 4 & $3.8 \pm 0.12$ & $3.7 \pm 0.06$ & $3.5 \pm 0.06$ & $3.4 \pm 0.03$ & $3.2 \pm 0.03$ \\
\hline & 6 & $5.5 \pm 0.22$ & $4.5 \pm 0.12$ & $3 \cdot 6 \pm 0.12$ & $3.9 \pm 0.06$ & $3.2 \pm 0.06$ \\
\hline & 8 & $15 \pm 2 \cdot 0$ & $6 \cdot 8 \pm 0.77$ & $5.4 \pm 0.34$ & $4.0 \pm 0.06$ & $3.3 \pm 0.12$ \\
\hline 2 & 9 & $37 \pm 3 \cdot 6$ & $8.9 \pm 0.93$ & $8 \cdot 2 \pm 0.77$ & $4 \cdot 3 \pm 0.40$ & $3 \cdot 2 \pm 0 \cdot 12$ \\
\hline 4 & 12 & $118 \pm 59$ & $23 \pm 4.6$ & $18 \pm 3.7$ & $4.2 \pm 0.09$ & $3.5 \pm 0.06$ \\
\hline 6 & 13 & $112 \pm 29$ & $38 \pm 9.8$ & $20 \pm 4 \cdot 7$ & II \pm 5.0 & $4.9 \pm 0.22$ \\
\hline 8 & 13 & $112 \pm 29$ & $35 \pm 11$ & $20 \pm 7 \cdot 8$ & II $\pm 2 \cdot I$ & $10 \pm 5.4$ \\
\hline
\end{tabular}

Portions from the zero-time samples were taken at $2 \mathrm{~h}$ intervals and fixed with formaldehyde (final concentration $\mathrm{I} \cdot 0 \%$, w/v) before microscopic examination. A single sample was taken from the flasks inoculated from the stock culture at 2, 4, 6 and $8 \mathrm{~h}$. The largest dimension of at least 100 germinating conidia was measured. This was used as the morphological criterion on which to base drug sensitivity (Table 3).

AME at $0 . \mathrm{I} \mu \mathrm{g} / \mathrm{ml}$ reduced the rate of conidial swelling and hyphal extension although it did not inhibit conidial germination (Table 3). At $>0.1 \mu \mathrm{g} / \mathrm{ml}$ there was a progressively greater degree of inhibition of conidial swelling and hyphal extension. Complete inhibition of both conidial swelling and hyphal extension occurred at $3.0 \mu \mathrm{g} \mathrm{AME} / \mathrm{ml}$.

\section{DISCUSSION}

The results of long-term growth tests show clearly the difficulty of interpreting these data when an unstable antibiotic is used, even though precautions are taken to minimize inactivation. The results of such tests give minimum inhibitory concentration (m.i.c.) values an order of magnitude higher than those based on conidial swelling or hyphal extension. Furthermore, the interpretation of tests on solid media is rendered difficult by the low solubility of the polyene, which makes it somewhat unlikely that a uniform antibiotic concentration can be achieved. 
Experiments in which conidia germinating in a liquid medium were treated with polyene before plating in antibiotic-free medium gave more informative and precise results; it is possible from such experiments to distinguish both a time-dependent and a concentrationdependent effect of the antibiotic. The longer that conidia were in contact with the antibiotic the greater the degree of inhibition of germination (Table I). Nevertheless, $30 \mu \mathrm{g} \mathrm{AME} / \mathrm{ml}$ did not completely inhibit conidial germination after $6 \mathrm{~h}$ exposure to the antibiotic. This survival of a limited number of conidia may have reflected some degree of reversibility, a variation in polyene sensitivity among the conidia, degradation of the antibiotic, or any combination of these factors, and could account for the high m.i.c. values recorded in plate assays. This observation may be relevant to the clinical situation where patients are exposed continually to conidia, and could explain why prolonged antibiotic therapy is required successfully to combat fungal infections.

The results of measuring $\mathrm{K}^{+}$release suggested that the addition or $3 \mu \mathrm{g} \mathrm{AME} / \mathrm{ml}$ to ungerminated conidia would allow germination to proceed as far as swelling when they become sensitive to this antibiotic concentration. However, this was not the case; the results of experiments using a morphological parameter as the criterion of antibiotic sensitivity demonstrated that $3 \mu \mathrm{g} \mathrm{AME} / \mathrm{ml}$ completely inhibited conidial swelling. This may reflect the time-dependent nature of the action of polyenes, in that the antibiotic was present throughout the growth experiment but was added after $4 \mathrm{~h}$ in the case of $\mathrm{K}^{+}$release. It was this observation which prompted us to perform the growth and viability experiments in which AME was added for $30 \mathrm{~min}$ (the maximum length of time necessary to assay $\mathrm{K}^{+}$ release) at various times during germination (Table 2 ).

A comparison of the results in Tables $I$ and 2 demonstrates that germinating conidia were more sensitive to AME inhibition if they were allowed initially to germinate in the absence of the antibiotic before brief exposure to it, than when the polyene was present throughout the incubation period. It would appear that the presence of the antibiotic during the early stages inhibits development, so that the stage at which germinating conidia become sensitive to AME is not reached. The difference in apparent sensitivity in these experiments may also reflect the instability of the polyene-AME has a half-life of $5 \mathrm{~h}$ in solution at $37^{\circ} \mathrm{C}$ at pH 6.8 (unpublished observation.) This inhibition must be reversible since long-term growth tests failed to reveal it. AME at $\mathrm{I} \mu \mathrm{g} / \mathrm{ml}$ inhibited conidial swelling during $8 \mathrm{~h}$ incubation (Table 3). On subsequent serial dilution and incubation in antibiotic-free medium, conidia germinated and produced visible mycelia (Table $\mathrm{I}$ ), which suggests that at this concentration AME is fungistatic to conidia. The results in Table 2 correlate well with those of Fig. 2 , where $\mathrm{K}^{+}$release is used as a measure of polyene sensitivity, and confirm the conclusion regarding the synchrony of germination (Fig. 2).

The time-dependent and concentration-dependent effects were also seen in the results of the experiments in which conidial swelling and hyphal extension were measured. Significantly, these experiments showed that at a concentration as low as $0 \cdot 1 \mu \mathrm{g}$ AME/ml both conidial swelling and hyphal extension were inhibited. This inhibition increased with antibiotic concentration until at $3 \mu \mathrm{g} / \mathrm{ml}$ there was a complete inhibition of conidial germination and hyphal extension, whether the antibiotic was present throughout germination or was added at any time up to $8 \mathrm{~h}$. As judged by these techniques the m.i.c. is $\mathrm{I}$ to $3 \mu \mathrm{g} \mathrm{AME} / \mathrm{ml}$; however, this gives no indication of any change during germination.

When $\mathrm{K}^{+}$release was used as the criterion of sensitivity, conidia became sensitive to I to $2 \mu \mathrm{g} \mathrm{AME} / \mathrm{ml}$ after $4 \mathrm{~h}$ incubation, i.e. during the swelling stage of germination. This level of sensitivity was maintained during outgrowth and extension of hyphae. The fact that there is good agreement between the growth-inhibitory values of I to $3 \mu \mathrm{g} \mathrm{AME} / \mathrm{ml}$ obtained 
when using a morphological parameter as the criterion of antibiotic sensitivity and the values when using $\mathrm{K}^{+}$release, demonstrates that the use of the $\mathrm{K}^{+}$electrode to monitor the polyene sensitivity of filamentous fungi is meaningful in terms of the antifungal action of the antibiotic. Furthermore, the use of $\mathrm{K}^{+}$release can give additional information on the changes in polyene sensitivity during germination which growth tests fail to detect. The change from the resistance of ungerminated conidia to the sensitivity of swollen conidia is very rapid and marked. The appearance of polyene sensitivity appears to be associated with the initial stages of 'phase darkening' and 'swelling' rather than with the outgrowth of germ tubes. The basis of this effect is at present under investigation.

The authors are indebted to Dr C. P. Schaffner for the gift of AME, to Mr J. T. Bokor for technical assistance, and to the Medical Research Council for financial support.

\section{REFERENCES}

Campbell, C. K. (I97I). Fine structure and physiology of conidial germination in Aspergillus fumigatus. Transactions of the British Mycological Society 57, 393-402.

Gale, E. F. (1974). The release of potassium ions from Candida albicans in the presence of polyene antibiotics. Journal of General Microbiology 8o, $45 \mathrm{I}-465$.

LAMPEN, J. O. (I966). Interference by polyene antifungal antibiotics (especially nystatin and filipin) with special membrane functions. Symposia of the Society for General Microbiology 16, 1 I I-130.

Zygmunt, W. A. (1966). Intracellular loss of potassium in Candida albicans after exposure to polyene antifungal antibiotics. Applied Microbiology 14, 953-956. 